\title{
The ABCDE-Model of counseling and psychotherapy: An integrative approach developed from clinical practice at a counseling service for students
}

\author{
Asimina Koutsoukou-Argyrak ${ }^{1,2 a}$, Frank-Hagen Hofmann ${ }^{1,2}$, Volker Kreß ${ }^{1,2}$, Michael \\ Sperth $^{1,2}$ and Rainer Matthias Holm-Hadulla ${ }^{1,2,3}$ \\ ${ }^{1}$ University of Heidelberg, Counseling Service for Students, Gartenstrasse 2, Heidelberg, 69115, \\ Germany \\ ${ }^{2}$ Heidelberg University Hospital, Centre for Psychosocial Medicine, Heidelberg, Germany \\ ${ }^{3}$ Facultad de Medicina, Universidad Diego Portales, Santiago, Chile
}

\begin{abstract}
A comprehensive model of integrative psychotherapy that has been derived from clinical practice at the Counseling Service for Students of the University of Heidelberg is outlined. The ABCDE-model of integrative psychotherapy is based on established therapeutic methods and is composed of the dimensions of Alliance, Behavior, Cognitions, Dynamics and Existentials. Based on the therapeutic alliance and the general principles of understanding and communication, it comprises cognitive-behavioral, psychodynamic, and existential elements and employs hermeneutics as a meta-theoretical framework. The evaluation of integrative counseling according to the ABCDE-model in a naturalistic single-group pre-post design demonstrated a clinically significant improvement within a rather short number of sessions. Therefore, the integrative model of psychotherapy is an important contribution to evidence-based practice. Moreover, models of training in psychotherapy and counseling for the better education of future therapists can be developed on the basis of the ABCDE-model.
\end{abstract}

Keywords: students; counseling; integrative; psychotherapy; cognitivebehavioral; psychodynamic

\section{Introduction}

Nowadays, students worldwide are being asked to adapt to the growing challenges of a constantly changing world.

\footnotetext{
${ }^{a}$ Corresponding author: Asimina.Koutsoukou@stw.uni-heidelberg.de
} 
Internationally increasing socioeconomic change, as well as specific educational reforms such as the implementation of the Bologna-Process that introduced significant changes in the European Education System [5], generate precariousness and encourage competitiveness among students. At the same time, students are expected not only to achieve academic and professional accomplishment, but also to develop personally as individuals, since they usually begin their studies at the sensitive age of post-adolescence. Finding companions, reestablishing relationships to parents and establishing new relationships, discovering independency, developing interests and preferred life-style, exploring their body image and sexuality, as well as setting personal and professional goals for their future, can be seen as a dynamic and challenging period of growth, rich in chances for development, as well as in distressing moments. Even though creativity research has shown that developmental crises contain a productive potential [24], the risk for developing mental disorders, as well as for being led to tragic outcomes, even suicide, is still high. Several studies have shown that suicidal ideation among college and university students is a central issue worldwide [38, 55, 58 and 61]. Also tragic incidents at educational institutes, such as campus shootings and murders, have raised international awareness [45]. And of course, even if such tragic outcomes are not the case, the possibility that a great number of students may fail to fulfil their personal and academic potentials already points to the current urgent need for ensuring adequate psychosocial factors that promote mental health, as well as for providing specialized supportive structures available at campus. The need to provide high quality of services in psychosocial counseling for students is an important professional issue worldwide [31].

\section{Current data on mental health of students internationally}

In the last 15 years, a growing prevalence of mental illness among young people has been observed [47]. Psychosocial factors affecting younger populations in general, along with stress and uncertainty in studies, constitute students a group that may be vulnerable to mental health problems. Already since the classical period in European culture, there have been descriptions of psychological crises, adjustment disorders, anxiety and depressive episodes, experienced by students of colleges and universities. An interesting phenomenological insight in the interplay of anxieties, depression episodes, dysthymia and creativity during studies can already be found in the case of the politician, scientist and poet J.W.v.Goethe [23, 32]. Nowadays, mental health of students draws increasingly the attention of the scientific research community. The high prevalence of mental disorders in student populations has been confirmed [62], while evidence for higher prevalence of psychological distress among university students in comparison to the general population has been found as well [54]. Interestingly, a much higher prescription rate of anti-depressive medication for students is also observed, when compared to young people of the same age not studying [47].

Recent data from the American College Health Association [1] state that $37 \%$ of college students in the United States had experienced feelings of overwhelming anxiety in the past year, while $9 \%$ report having attempted suicide at some point in their lifetime. Interference of emotional or stress-related problems of students with their academic performance or their personal well-being was reported by $44 \%$ of international graduate students questioned in a study by Hyun and colleagues [34]. Relevant necessary considerations further involve the interaction of mental disorders and stress with identity development [47]. In this respect, it should be taken into account that also financial problems or, in the case of international students, problems with health insurance, job or residence permit increase the perceived stress level [41].

The first counseling services for students, initially focusing on career counseling and assessment, were established in the United States in the late 1940s, while personal counseling and psychotherapy gradually became a focus in the 1960s [45]. Today, the primary mental 
disorders reported at counseling services for students are anxiety and depression, as well as academic problems and adverse life events $[17,57]$. Studies conducted in the UK, Sweden, Norway and Germany report prevalence rates of mental health problems among students of between $20 \%$ and $25 \%$ [36]. Training and licensing requirements for staff members of counseling services for students are evidently the sine qua non of assuring high quality of services. Providing internationally informed and culturally congruent counseling and mental health services should be a central concern [7].

Regarding the development of the mental health of students over time, there are several studies showing an increase in mental health problems of students [10, 43]. Such a development is also evident on data concerning the demand for consultation at counseling services for students. For example, the demand for consultation at the University of Chile increased by almost $80 \%$ between 2010 and 2014 [57]. Also a collection of data from onlinequestionnaires given to 28 counseling center directors over 20 years confirms an increase in student pathology and in demand for appointments [18]. Nevertheless, there are also indications for stability in type and extent of psychological distress reported by clients of student counseling service [29] or even a decrease in self-reported mental health problems [5]. While it is possible that changes in the client-perceived distress may not necessarily reflect real changes, rather than the influence of media attention or high-profile cases on a higher reactivity to psychological symptoms [50], the necessity for more systematic research on the mental health of students is profound.

\section{The situation in Germany}

In Germany, a nationwide representative study of $1995(n=20.000)$ showed that $27 \%$ of university students reported impairment in their studies caused by psychological distress. As much as $10 \%$ of all students reported feeling severely impaired. The main problems reported were difficulties with academic performance, lacking self-esteem, depressiveness, test anxiety and general anxiety [19].

A recent study at the University of Heidelberg compared field samples with samples of clients of the counseling service for students from the last 15 years. While $12-15 \%$ of the students in the field sample are severely impaired, severe mental health disorders affect 54$58 \%$ of the clients of the counseling center. This confirms preliminary studies, according to which about $50-60 \%$ of the client center students are severely mentally impaired. At least half of the clients of the students counseling service are suffering from clinically relevant disorders. The main problems reported by university students are diffuse anxieties, depressive moods, lack of self-esteem, psychosomatic symptoms, study-related complaints such as test anxiety and work and concentration difficulties, alcohol and substance abuse, as well as suicidality [36].

The main tasks of well-trained counselors and psychotherapists at the counseling services for students are assisting in coping with psychosocial crises and preventing mental disorders, suicide and violence. Crisis intervention and short-term psychotherapy is also offered at the counseling services of some universities. As a matter of fact, the tasks of the counseling service involve diagnosis, crisis intervention, counseling, short-term psychotherapy and further placement of patients suffering from clinically relevant disorder [36].

At the University of Heidelberg, besides individual counseling, also group counseling is offered, focusing on the improvement of social competences of students and the elimination of their academic problems, as well as supporting them in overcoming psychic disability. Furthermore, also counseling by phone and online is an option offered to students.

Both type and extent of psychological distress in clients consulting the psychosocial counselling center of the University of Heidelberg remained rather stable between 1993 and 2008, with the exception of somatoform disorders and test anxiety showing an increase [29]. 
A comparison of the prevalence of psychological distress in medical and psychology students at the University of Heidelberg between 1994 and 2012 even showed a decrease in selfreported mental health problems. The improvement of health care, economic conditions and study conditions may be possible explanations for this development [5].

\section{The ABCDE-Model of integrative counseling}

Student counseling has become an important professional issue throughout the world, where overlaps with short-term psychotherapy and coaching can be found [25]. Several integrative frameworks have been developed that are founded on different psychotherapeutic approaches [39, 40, 44 and 56]. However, the need for an integrative model of psychotherapy and counseling that combines different psychotherapeutic strategies in a comprehensive way is still profound.

The ABCDE-model of integrative psychotherapy, developed at the Counseling Service for Students of the University of Heidelberg, is based on established therapeutic methods and is composed of the dimensions of Alliance, Behavior, Cognitions, Dynamics and Existentials. Focusing upon the construction of a helping therapeutic relationship, this model incorporates behavioral, cognitive, psychodynamic and existential elements, integrating theoretical perspectives and therapeutic strategies that are derived from client-centered, cognitivebehavioral, psychodynamic and existential psychotherapy [28]. A central topic of the psychotherapeutic approaches that inspired our own model of integrative psychotherapy is the improvement of psychological and social coherence [2]. The integrative model proposed here is organized within the metatheoretical framework of modern hermeneutics [16], outlining basic principles of helpful communication as a key element of psychotherapy [26]. Neurobiological, psychological and cultural studies demonstrate the importance of understanding and communication for the enhancement of emotional and cognitive coherence [22].

The dimension of Alliance refers to the therapeutic relationship, conceived as a stable and helping alliance between patient and therapist. The importance of the relationship between therapist and patient is an essential psychotherapeutic principle for every school of psychotherapy, present in the humanistic approach of Carl Rogers (1957), in existential psychotherapy [13, 60], in modern psychoanalysis [35], as well as in cognitive-behavioral therapy approaches [20] and is seen as a key-important parameter-the basis of every psychotherapeutic success [37]. Also neurobiological evidence stresses the importance of attentiveness and empathy for positive communication [6]. In our model, a respectful, attentive and empathic therapeutic relationship constitute the basis of counseling and psychotherapy.

The dimension of Behavior, which is based upon behavioral therapy approaches developed from theories of classic and operant conditioning $[42,52]$ and the social learning theory [3], aims at the modification of dysfunctional behavior patterns through advice on target-oriented behavior rules, as well as through the effective use of positive reinforcement. Through a positive reinforcing setting, role-plays and of course talking in a normal way about troubling thoughts, the client is able to discover functional alternative behavior patterns, as well as to develop new implicit attitudes and values [21].

Originating from cognitive therapy (Beck, 2004) and rational emotive behavior therapy [9], the dimension of Cognitions focuses on the systematic modification and correction of dysfunctional meanings, values and beliefs [28]. According to cognitive approaches, the reaction to a situation is not direct, but to a great extent influenced by the conscious and unconscious appraisal of the situation, which in turn depends on the attitudes, values and beliefs a person holds. Therefore, the correction of distorted cognitions can have an important impact on the therapeutic work towards elimination of dysfunctional behavior and reduction 
of distress. Questioning the belief system of the client on the basis of the socratic method of discussion, the counselor enables him to realize its inconsistencies and dysfunctional aspects, leading him step-by-step to the development and consolidation of a new, functional belief system [21].

Dynamics stands for the dynamics of unconscious psychic processes (psychodynamics), reprocessed and restructured into a coherent mental representation [11] through psychotherapeutic work on memories, feelings and conflicts. Psychodynamic psychotherapy underlines the importance of unconscious conflicts for psychic well-being [14]. Within the framework of psychodynamic psychotherapy, a sheltered space is provided where the patient can ,play“ with memories, imagination, associations and affects [59]. The reflection on the patient's personal history and the consideration of central relationship conflicts allow the clarification and confrontation with conscious and subconscious processes. Also understanding transference and countertransference, even without essentially addressing these constructs, enable gaining insight to such psychic processes [53].

The dimension of Existentials, inspired from existential psychotherapy and focusing upon the position of an individual in relation to the world [28], introduces the processing of central existential subjects such as responsibility, death, freedom, isolation, creativity or the meaning of life [60]. According to existential therapists, mental disturbances are often the consequence of an attempt to escape from reality and its philosophical meaning [13], therefore the therapeutic work on existential themes ,assists the patient in coming to terms with contradictions, dilemmas and paradoxes of their everyday existence“"[56]. The ABCDEmodel of integrative counseling and psychotherapy does not concentrate exclusively on these subjects, but places the main focus upon the general principles of understanding and communicating as basic movements of human existence [16] and also integrates aspects of creativity research and positive psychology [49], providing the client a helpful attendant at the search for meaning.

Central active principles of modern hermeneutics that allow their implementation in the dynamic process of integrative counseling and psychotherapy as a fundamental element of relational communication are memory, narrative shaping, and interactional experience [25, 26]. Reflecting on past experiences in the context of the therapeutic relationship can give new meaning to past events and influence actively the present actions of the client. Creating and communicating verbal and other representations of conscious and unconscious experiences which remained to be inaccessible contributes to their integration into a coherent constellation of psychic experiences. Moreover, the interactional therapeutic experience focuses on the creative dynamic dialogue between counselor and client, where the latter is free to integrate or modify the subjective representations triggered to the counselor as response to the client's narration [53].

\section{Evaluation of the effectivity of the ABCDE-Model of integrative counseling and psychotherapy}

The effectiveness of the ABCDE-Model of Integrative Counseling was evaluated in a naturalistic single-group pre-post design [21]. Students consulting the counseling center for students at the University of Heidelberg were asked to complete a questionnaire prior to the first counseling session that included the German version of the Symptom-Checklist 90- R [12], the Psychosocial Complaints List (PCL) [33], and the Satisfaction with Life and Studies Scale (SLS) [30]. After the initial session, the counselors were required to rate the GAF score based on the German version of the DSM-IV-TR [48] and to provide diagnoses according to the ICD-10 [8]. Client ratings were compared to student norms or to scores of a student field sample [29]. Pre-post effect sizes for mental distress (SCL-90-R, PCL, and GAF) and 
satisfaction measures (SLS) were calculated and statistical and clinical significances for the GSI (SCL-90-R) and the PCL sum score were computed.

Out of the total of 569 clients that consulted the counseling center during the survey period, 254 were referred to other forms of treatment (mostly outpatient psychotherapy) and the resting 315 clients that remained at the counseling center received a psychotherapeutic counseling based on the integrative ABCDE-model. Weekly discussions between counselors assured an adherent conceptualization of the counseling process according to the different levels of the model and respecting the individual and momentary needs of the clients. After completion of the counseling process, clients were asked to fill out the questionnaire again. 151 clients meeting the inclusion criteria provided post-data corresponding to a return rate of $47.9 \%$ (completers). The mean number of sessions was $6.20(\mathrm{SD}=4.11)$ in $14.04(\mathrm{SD}=12.96)$ weeks. Mean age at initial contact was 25.32 years $(\mathrm{SD}=3.78)$ and $71.5 \%$ of the clients were female.

Prior to the initial counseling session, completers were significantly more distressed $(\mathrm{p}<0.001)$ by physical and psychological symptoms, compared to the norm sample of students, with the exception of the paranoid ideation subscale. After counseling, no significant mean differences in obsessive-compulsive symptoms and anxiety between completers and student sample were found anymore. A significantly higher distress of completers when compared to the field student sample was also evident on the Psychosocial Complaint list. Again, the significant differences vanished after completion of the counseling process. Satisfaction with life and studies also showed a significant improvement after counseling, and reached a similar level to the one reported by the field student sample. For the Global Assessment of Functioning (GAF) as rated by counselors, the share of clinically impaired clients was reduced from $47.5 \%$ to $3.5 \%$.

The results demonstrate a clinical significant efficacy of integrative counseling according to the ABCDE-model in reducing severity of psychopathology and increasing satisfaction with life and studies within a short number of sessions, confirming existing findings on the efficacy of psychotherapy [51].

Having been conducted as a field research within a mental health care center, our pilot study demonstrates a high external validity [15], yet a low internal validity, so that the positive effects of the counseling process cannot be attributed to the treatment exclusively. As critical points can be mentioned the lack of control group, as well as the perhaps inadequately assured adherence. The exact working mechanisms of the different aspects of integrative counseling at different stages of the therapeutic process, as well as the differentiated effects for each type of clients should be closely investigated in future research [21].

\section{Conclusion}

In conclusion, the integrative approach on counseling and psychotherapy incorporates science-based and practice-oriented psychotherapeutic concepts and brings essential benefits to primary psychosocial care, as well as to the development of training programs for future therapists.

The ABCDE model of integrative counseling and psychotherapy combines working mechanisms of different psychotherapeutic approaches and provides a structured and at the same time flexible setting that is adaptable to specific configuration of the client's personal needs. Our integrative approach allows for a creative meta-theoretical integration and an actively interchangeable focus on the several aspects of psychotherapy, so that the limitations associated with technical eclecticism are surpassed.

As improvement rates in all measures in the pilot study conducted at a clinical mental health setting show a clinically significant improvement, this integrative model of 
psychotherapy is an important contribution to evidence-based practice. Moreover, this study raises important research questions for the future development of integrative psychotherapy. A detailed operationalization of the different dimensions of the ABCDE-model is necessary, so that the working mechanisms are explored and correctly used with the utmost benefits for different types of clients.

This study has important implications for the education of future therapists as well. Models of training in psychotherapy and counseling can be developed from the ABCDEmodel. The individual aspect of our model of integrative psychotherapy can be learnt in a master program for psychologists, while future therapists can decide which kind of specialization fits to their emotional and cognitive styles. Integrating different concepts into the curriculum of studies for future psychotherapists may also encourage the thoughtful communication among therapists with different educational backgrounds and allow the successful integration of multiple theoretical concepts in the therapeutic practice, with important benefits for the patients and clients. Furthermore, the benefits of competent method integration for a great number of patients should be manifest to therapists adhering to methods like cognitive-behavior therapy or psychodynamic therapy.

\section{References}

1. American College Health Association. American College Health Association-National College Health Assessment II: Reference Group Executive Summary Spring 2014. Hanover, MD: American College Health Association., (2014).

2. Antonovsky, A. The salutogenic perspective: toward a new view of health and illness. Advances, 4, 47-55., (1987).

3. Bandura, A. Social learning theory. Englewood Cliffs, NJ: Prentice-Hall., (1977).

4. Beck, A. Cognitive therapy and the emotional disorders. New York: International Universities Press., (1976).

5. Berger, H., Franke, G.H., Hofmann, F.-H., Sperth, M., \& Holm-Hadulla, R. Mental health of students and its development between 1994 and 2012. Mental Health \& Prevention, http://dx.doi.org/10.1016/j.mhp.2015.01.001., (2015).

6. Carhart-Harris,R.L., \& Friston, K.J. The default-mode, ego-functions and free-energy: A neurobiological account of Freudian ideas. Brain: A Journal of Neurology, 133(4), 1265-1283., (2010).

7. Davidson, L., \& Locke, J.H. Using a public health approach to address student mental health. In J.Kay, \& V.Schwartz (Eds), Mental health in the college community (pp.267288). Hoboken, NJ: John Wiley \& Sons Ltd., (2010).

8. Dilling, H. Internationale Klassifikation psychischer Störungen: ICD-10 Kapitel V (F); diagnostische Kritierien für Forschung und Praxis (4., überarb. Aufl). Bern [u.a.]: Huber., (2006).

9. Ellis, A. Reason and Emotion in Psychotherapy. Secaucus, Lyle Stuart., (1962).

10. Erdur-Baker, O., Aberson, C. L., Barrow, J. C., \& Draper, M. R. Nature and severity of college students' psychological concerns: A comparison of clinical and nonclinical national samples. Professional Psychology: Research and Practice, 37(3),317 - 323., (2006).

11. Fonagy, P., \& Target, M. (Eds). Psychoanalytic theories: Perspectives from developmental psychopathology. Philadelphia: PA, Whurr Publishers., (2003).

12. Franke, G.H., \& Derogatis, L.R. SCL-90- R: Symptom-Checkliste von L. R. Derogatis; Dt. Version. Göttingen: Beltz Test., (2002).

13. Frankl, V. Der leidende Mensch. Anthropologische Grundlagen der Psychotherapie. Bern: Huber., (2005).

14. Freud, S. (1914). Remembering, repeating and working through. London: Hogarth. 
15. Fydrich, T., \& Schneider, S. Evidenzbasierte Psychotherapie. Psychotherapeut, 52 (1), 55-68, http://dx.doi.org/10.1007/s00278-006-0522-x., (2007).

16. Gadamer, H.G. Philosophical Hermeneutics. Berkeley: University of California Press., (1976).

17. Gallagher, R.P. National survey of our counseling center directors. [Online]., (2013). Available at: http://www.collegecounseling.org/wp-content/uploads/Survey-2013-4-yrDirectors-1.pdf

18. Grayson, P., Meilman, P. Longevity speaks: observations from long-serving counseling directors. Journal of College Student Psychotherapy, 27(3), 185-199., (2013).

19. Hahne, R. (1999). Studium und psychische Probleme. Sonderauswertung zur 15.Sozialerhebung des Deutschen Studentenwerks. Bonn: Dt. Studentenwerk.

20. Hautzinger, M. Kognitive Verhaltenstherapie der Depressionen. Weinheim: Beltz., (2013).

21. Hofmann, F.-H., Sperth, M., \& Holm-Hadulla, R.M. Methods and effects of integrative counseling and short-term psychotherapy for students, Mental Health and Prevention, (2015). http://dx.doi.org/10.1016/j.mph.2015.04.005.

22. Holm-Hadulla, R.M. The dialectic of creativity: a synthesis of neurobiological, psychological, cultural and practical aspects of the creative process. Creativity Research Journal, 25 (3), 293-299, (2013). http://dx.doi.org/10.1080/10400419.2013.813792.

23. Holm-Hadulla, R.M. Goethe's Anxieties, depressive Episodes and self-therapeutic strategies: a contribution to method integration in psychotherapy. Psychopathology, 46, 266-274., (2012).

24. Holm-Hadulla, R.M. Allgemeine und Hermeneutische Psychotherapie.Psychotherapeut, 41, S. 355-360., (1996).

25. Holm-Hadulla, R.M. The art of counselling and psychotherapy. London: Karnac., (2004).

26. Holm-Hadulla, R.M., The creative aspect of dynamic psychotherapy: parallels between the construction of experienced reality in the literary and the psychotherapeutic process. American Journal of Psychotherapy, 50(3), 360-369., (1996).

27. Holm-Hadulla, R.M., Hofmann, F.-H. Counseling, psychotherapy and creativity. Asia Pasific Journal of Counselling and Psychotherapy, 3(2), 130-136., (2012).

28. Holm-Hadulla, R.M., Hofmann, F.-H., \& Sperth, M. An integrative model of counseling. Asia Pacific Journal of Counselling and Psychotherapy, 2(1), 3-24., (2011).

29. Holm-Hadulla, R.M., Hofmann, F.-H., Sperth, M., \& Funke, J. Psychische Beschwerden und Störungen von Studierenden. Psychotherapeut, 54, 346-356., (2009).

30. Holm-Hadulla, R.M., \& Hofmann, F.-H. Lebens- und Studienzufriedenheitsskala. Unpublished., (2007).

31. Holm-Hadulla, R.M., \& Koutsoukou-Argyraki, A. (2015). Mental health of students in a globalized world, prevalence of complaints and disorders, methods and effectivity of counseling, structure of mental health services. Mental Health and Prevention, http://dx.doi.org/10.1016/j.mhp.2015.04.003.

32. Holm-Hadulla, R.M., Roussel, M., \& Hofmann, F.-H. Depression and creativity: the case of the German statesman, scientist and poet J.W.v.Goethe. Journal of Affective Disorders, 127, 43-49., (2010).

33. Holm-Hadulla, R.M., \& Soeder, U. Psychische Beschwerden und Störungen von Studierenden. Psychotherapie Psychosomatik Medizinische Psychologie, 47 (12), 419 425., (1997).

34. Hyun, J., Quinn, B., Madon, T., \& Lustig, S. Mental health needs, awareness, and use of counseling services among international graduate students. Journal of American College Health, 56, 109-118.,. (2007). 
35. Kernberg, O. Schwere Persönlichkeitsstörungen: Theorie, Diagnose, Behandlungsstrategien. Stuttgart: Klett-Cotta., (2013).

36. Kress, V., Sperth, M., Hofmann, F.-H., \& Holm-Hadulla, R.M. Psychological complaints and disorders of students: a comparison of field samples with clients of a counseling service at a typical German university. Mental Health and Prevention, (2015).http://dx.doi:10.1016/j.mhp.2015.04.002.

37. Lambert, M.J. Bergin and Garfield's Handbook of Psychotherapy and Behavior Change. (6th ed. ) New York: John Wiley \& Sons., (2013).

38. Lamis, D.A., \& Lester, D. Understanding and Preventing College Student Suicide. Springfield, IL US: Charles C Thomas Publisher.

39. Lazarus, A.A. (1976). Multimodal behavior therapy. Springer series in behavior modification. New York: Springer Pub. Co., (2011).

40. Orlinsky, D.E., Ronnestad, M.H., \& Willutski, U. Fifty years of psychotherapy processoutcome research: continuity and change. In: M.J. Lambert (Ed.) Handbook of psychotherapy and behavior change (5th Ed.) (pp. 207-291), New York: John Wiley \& Sons., (2004).

41. Ortenburger, A. Beratung von Bachelorstudierenden in Studium und Alltag. HIS: Forum Hochschule, Deutsches Studentenwerk., (2013).

42. Pawlow, I.P. Conditioned reflexes: An investigation of the physiological activity of the cerebral cortex. London: Oxford University Press., (1927).

43. Pledge, D. S., Lapan, R. T., Heppner, P. P., Kivlighan, D., \& Roehlke, H. J. Stability and severity of presenting problems at a university counseling center: A 6-year analysis. Professional Psychology: Research and Practice, 29 (4), 386 - 389., (1998).

44. Prochaska, J.O., \& Norcross, J.C. Systems of psychotherapy: A transtheoretical analysis (6th ed). Australia: Thomson/Brooks/Cole., (2007).

45. Prince, J. P. University student counseling and mental health in the United States: Trends and challenges. Mental Health \& Prevention, (2015). http://dx.doi.org/10.1016/j.mhp.2015.03.001.

46. Rogers,C.R. The necessary and sufficient conditions of therapeutic personality change. Journal of Consulting Psychology, 21, 95-103., (1957).

47. Rückert, H.W. Mental health of students and psychological counseling in Europe. Mental Health and Prevention, (2015). http://dx.doi.org/10.1016/j.mhp.2015.04.006.

48. Sass, H. Diagnostisches und statistisches Manual psychischer Störungen: Textrevision DSM-IV-TR. Göttingen [u.a.]: Hogrefe., (2003).

49. Seligman, M.E., \& Csikszentmihalyi, M. Positive psychology. an introduction. The American psychologist, 55 (1), 5-14., (2000).

50. Sharkin, B.S., \& Coulter, L.P. Empirically supporting the increasing severity of college counseling center client problems: why is it so challenging? Journal of College Counseling, 8(2), 165-171., (2005).

51. Shapiro, D.A., \& Shapiro, D. Meta-analysis of comparative therapy outcome studies: a replication and refinement. Psychological Bulletin, 92 (3), 581-604., (1982).

52. Skinner, B.F. Science and human behavior. New York: Free Press., (1953).

53. Sperth, M., Hofmann, F.-H., \& Holm-Hadulla, R.M. Integrative Psychologische und Psychotherapeutische Beratung für Studierende. Zeitschrift für Beratung und Studium, Universitätsverlag Webler., (2009).

54. Stallman, H.M. Psychological distress in university students: a comparison with general population data. Australian Psychologist, 45(4), 249-257., (2010).

55. Toprak, S., Cetin, I., Guven, T., Can, G., \& Demircan, C. Self-harm, suicidal ideation and suicide attempts among college students. Psychiatry Research, 187, 140-144., (2011). 
56. Van Deurzen, E. Existential counseling and psychotherapy. In C. Feltham \& I. Horton (Eds.), The SAGE handbook of counseling and psychotherapy (pp-281-285) ( 2nd ed). London: SAGE., (2006).

57. Villacura, L.A., Irarrázabal, N., Dörr, A., Zamorano, C., Manossalva, J. Cánovas, C., Zamorano, M., \& Barra, N. Mental disorders of students and mental health services at the university of Chile. Mental Health and Prevention, (2015). http://dx.doi.org/10.1016/j.mhp.2015.05.002.

58. Wilcox, H.C., Arria, A.M., Caldeira, K.M., Vincent, K. B., Pinchevsky, G. M., \& O'Grady, K. E.. Prevalence and predictors of persistent suicide ideation, plans, and attempts during college. Journal of Affective Disorders, 27 (1-3), 287-294., (2010)

59. Winnicott, D.W. Playing and Reality. London: Tavistock., (1971).

60. Yalom, I.. Existential Psychotherapy. New York: Basic Books., (1980)

61. Zhang, X., Wang, H., Xia, Y., Liu, X., \& Jung, E. Stress, coping and suicide ideation in Chinese college students. Journal of Adolescence 35(3), 683-690., (2012).

62. Zivin, K., Eisenberg, D., Gollust, S.E., \& Golverstein, E. Persistence of mental health problems and needs in a college student population. Journal of Affective Disorders, 117(3), 180-185., (2009). 